\title{
2,5-diketopiperazines mitigate the amount of advanced glycation end-products accumulated with age in human dermal fibroblasts
}

A. André*, , A. K. Touré†, D. Stien‡ and V. Eparvier ${ }^{\dagger}$

${ }^{*}$ CNRS, Institut de Chimie des Substances Naturelles, UPR 2301, Université Paris-Saclay, 1 avenue de la Terrasse, Gif-sur-Yvette 91198, France

†Laboratoire Shigeta, 62 boulevard Davout, Paris 75020, France

‡Laboratoire de Biodiversité et Biotechnologies Microbiennes, Sorbonne

Université, CNRS, USR 3579, Banyuls-sur-mer 66650, France 


\section{ABSTRACT}

OBJECTIVE: Glycation is a common non-enzymatic reaction between proteins and sugars, resulting in the formation of advanced glycation end products (AGEs) in the human body. As can be seen in diabetic patients, the accumulation of AGEs in the skin has aesthetic consequences (wrinkles, brown spots, yellowish complexion). Therefore, the objective of this work was to find compounds isolated from natural sources that could eliminate the final AGEs accumulated in the skin with aging.

METHODS \& RESULTS: A preliminary screening performed on a bank of microbial extracts and pure compounds showed that 2,5-Diketopiperazines (DKPs), as well as the extract of Sphingobacterium sp (SNB-CN13), reduced the presence of AGEs in fibroblasts by $-28 \%$ and $-23 \%$ respectively. In this article, we present the dereplication approach used to reveal the presence of 26 different DKPs in the crude extract of Sphingobacterium sp. Bioguided fractionation has led to the isolation of 12 of them, whose identity has been confirmed by HRMS and NMR. A green synthesis approach has been developed to synthesize 3 symmetrical DKPs. The biological activity of all DKPs was evaluated by the development of an in vitro test using immunocytochemistry to reveal the presence of AGE carboxymethyl-lysine in human dermal fibroblasts.

CONCLUSION: Our work shows for the first time that DKPs decrease the amount of carboxymethyl-lysine AGE in elderly human dermal fibroblasts grown in vitro. Therefore, diketopiperazines can be considered as compounds of interest for dermatological and cosmetic applications with an anti-ageing aim. 
Cell culture ; chemical analysis ; skin physiology ; 2,5-diketopiperazines ; molecular networks ; AGEs/CML clearance. 


\section{INTRODUCTION}

Louis-Camille Maillard described the glycation reaction for the first time in 1912 (1). This naturally occurring non-enzymatic reaction between reducing sugars and aminoacid residues of proteins leads to the formation of a complex and heterogenous group of compounds named advanced glycation end-products (AGEs).

AGEs accumulate in the whole body during the lifetime, both in the extra- and intracellular environments (2). Long lifespan proteins of the body, like collagen, elastin and hemoglobin are well-known targets of irreversible modifications caused by the glycation reaction (3).

At the extracellular level, proteins crosslinking induces inhibition of cell growth, impaired cell adhesion, and tissue dysfunction (4). At the intracellular level, AGEs cause cell damage directly by altering protein functions, and indirectly by producing reactive oxygen species (ROS) (5). Excessive levels of ROS can then alter cell detoxification systems such as the proteasome, as well as the enzymes involved in cell repair (6). AGEs can also bind to the Receptor of Advanced Glycation End products (RAGE), triggering the

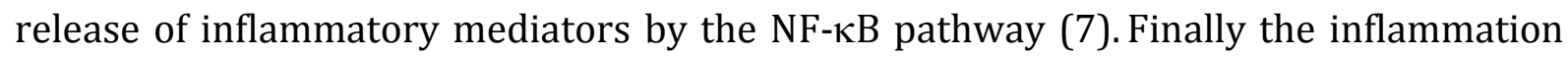
and oxidation reactions triggered by AGEs will result in the formation of more AGEs in cells. These phenomena also reduce the antioxidant and repair potential of cells, which will eventually lead to dysfunction of tissues and organs (8). Consequently, AGEs are considered to be the main agents responsible for many age-related diseases (3) such as diabetic vascular complications (9), atherosclerosis (10), or Alzheimer's disease (11).

The glycation reaction does not spare the skin. AGEs have been shown to accumulate in both the dermis and epidermis (12,13). Pentosidine, a fluorescent AGE, and carboxymethyl-lysine, an AGE that forms protein adducts, are the two main final glycation products found in the skin (12). The accumulation of AGEs in the intra- and 
extracellular skin environment causes, among other things, a stiffening of collagen, elastin or fibronectin fibers, as well as an increase in melanogenesis $(14,15)$. The skin is thus less elastic and more sensitive to the various mechanical stimuli it endures. Also, the complexion is more yellow and less homogeneous, which inevitably affects its youthful appearance overtime (15-17), as seen in people with diabetes $(19,20)$. Most compounds on the cosmetic market act by preventing or reversing the first step of the glycation reaction, i.e., the binding between proteins and sugars leading to the formation early glycation products, also called Amadori products. Looking at their mode of action, none of these ingredients really affect the reduction in the amount of final AGEs present in elderly cells. Therefore, the dermatological, cosmetic and therapeutic interest in discovering compounds that reduce the amount of AGEs accumulated in skin is important.

In this context, we screened a bank of pure compounds and microbial extracts to find suitable candidates to reduce both the total amount of AGEs, and the amount of pentosidine in human dermal fibroblasts (21). During screening, molecules belonging to the family of 2,5-diketopiperazines, and an ethyl acetate extract of Sphingobacterium sp. (SNB-CN13) showed a reduction in AGE content of fibroblasts by more than $20 \%$. In this article, we present for the first time the activity of naturally occurring 2,5-DKP on the elimination of carboxymethyl lysine AGE (CML) in human dermal fibroblasts and evaluate their potential as active ingredients in dermatology and cosmetics.

\section{MATERIAL AND METHODS}

General experimental procedures. Optical rotations were measured on an Anton Paar MCP 300 polarimeter in a $100 \mathrm{~mm}$-long $350 \mu \mathrm{L}$ cell. UV spectra were recorded using a Perkin-Elmer Lamba 5 spectrophotometer. CD spectra were measured at $25^{\circ} \mathrm{C}$ on a 
JASCO J-810 spectropolarimeter. Nuclear Magnetic Resonance (NMR) spectra were recorded on a Bruker $500 \mathrm{MHz}$ spectrometer or a Bruker $600 \mathrm{MHz}$ spectrometer equipped with a $1 \mathrm{~mm}$ inverse detection probe. Chemical shifts $(\delta)$ are reported in ppm based on TMS signal, and coupling constants (J) are reported in Hertz. HRESIMS measurements were performed using a Waters Acquity UHPLC system with column bypass coupled to a Waters Micromass LCT premier Time-of-Flight mass spectrometer (Milford, Ma, USA) equipped with an electrospray interface (ESI). X-ray diffraction data for compound $\mathbf{1 1}$ were obtained at room temperature on a Rigaku Rapid II diffractometer equipped with a rotating anode mm007 HF generator and Osmic mirrors $(\mathrm{Cu} \mathrm{K} \alpha$ radiation, $\lambda=1.54187 \AA$ ) using $\omega$-scans. Data were indexed, integrated and scaled using CrystalClear(22). They were also corrected for polarization, Lorentz and absorption effects (FS_ABSCOR). X-ray diffraction data for compound $\mathbf{2 0}$ were obtained at room temperature on a Rigaku XtaLabPro diffractometer equipped with a microfocus source (MicroMax003_Mo) and multilayer confocal mirrors (Mo K $\alpha$ radiation, $\lambda=$ $0.71073 \AA$ A). Data were indexed, integrated and scaled using CrysalisPro. They were also corrected for polarization, Lorentz and absorption effects (SCALE3 ABSPACK). For each compound, the structure was solved with the ShelXT (23) structure solution program using Direct Methods and refined with the ShelXL (24) refinement package using Least Squares minimization. All non-hydrogen atoms were refined with anisotropic displacement parameters and $\mathrm{H}$ atoms have been added geometrically and treated as riding on their parent atoms. Molecular graphics were computed with Ortep 3 (25). Flash chromatography was performed on a Grace Reveleris system with dual UV and ELSD detection equipped with a 120 g C18 column. For UV-based experiments, effluents were monitored at 254 and $280 \mathrm{~nm}$. Analytical and preparative HPLCs were conducted on a Gilson system equipped with a 322 pumping device, a GX-271 fraction collector, a 
171 diode array detector and a prepELSII detector electrospray nebulizer. Columns used for these experiments included: a Phenomenex Luna $\mathrm{C}_{18}$ or PFP (2) $5 \mu \mathrm{m} 4.6$ x $250 \mathrm{~mm}$ analytical column, and Phenomenex Luna $C_{18}$ or PFP (2) $5 \mu \mathrm{m} 21.2$ x $250 \mathrm{~mm}$ preparative column. The flow rate was set to 1 or $21 \mathrm{~mL} / \mathrm{min}$ respectively, using a linear gradient of water mixed with an increasing proportion of acetonitrile. All solvents were HPL grade and supplemented with $0.1 \%$ of formic acid. The Mueller-Hinton (MH) was purchased from Conda. TritonX-100 was from Euromedex (Euromedex France, Souffelweyersheim, France). DMSO was obtained from Carlo Erba (Carlo Erba Reagents S.A.S, Val de Reuil, France). Tween-20 was obtained from Acros Organics (Acros Organics, Geel, Belgium). Bovine serum albumin (BSA) was obtained from Dutscher (Dominique Dutscher SAS, Brumath, France). Paraformaldehyde was obtained from Electron Microscopy Science (EMS, Hartfield, PA, U.S.A). Mouse anti-CarboxyMethylLysine (CML) antibody (KH011) was obtained from Cosmo Bio Co (Cosmo Bio Co LTD, Tokyo, Japan). Goat anti-mouse secondary antibody Alexa-488 conjugate (A11017) was obtained from Lifetechnologies (ThermoFisher Scientific, Waltham, MA, U.S.A). Mounting medium with DAPI was obtained from Vector (Vector Laboratories Inc, Burlingame, CA, U.S.A).

Isolation and identification of Sphingobacterium spp. SNB-CN13. Pieces of termite nests were collected and cultured as described in our previous work (26). The procedure adopted for identification of the strain was also describe in the same article (26), and the strain was saved at $-80{ }^{\circ} \mathrm{C}$ at the Métabolites de micro-organismes symbiotiques - Bioinspiration laboratory, ICSN/CNRS, France. The bacteria rDNA sequence obtained was aligned with sequences from GenBank, NCBI (http://www.ncbi.nlm.nih.gov/genbank/ consulted on December 15, 2019), indicating 
that SNB-CN13 was closely related to Sphigobacterium species. The sequence was deposited on the GenBank with the accession number FJ959369.1.

Culture of bacterium, extraction and isolation of compounds. Sphingobacterium sp. was cultivated on solid Mueller-Hinton medium at $28^{\circ} \mathrm{C}$ for one week on 101 Petri dishes that were $14 \mathrm{~cm}$ in diameter (total $1.4 \mathrm{~m}^{2}$ ). The contents of the Petri dishes were cut into small pieces, transferred into a large container and macerated with ethyl acetate for 24 hours. The organic solvent was collected via filtration, washed with water in a separating funnel, and evaporated to dryness under reduce pressure to yield $3.24 \mathrm{~g}$ (2.3 $\left.\mathrm{g} / \mathrm{m}^{2}\right)$.

A portion of the ethyl acetate extract (2.6 g) was fractionated using flash chromatography using a gradient of water mixed with increased proportions of acetonitrile $\left(\mathrm{H}_{2} \mathrm{O}: \mathrm{CH}_{3} \mathrm{CN} 95: 5-80: 20-50: 50-20-80-0: 100\right)$ at $80 \mathrm{~mL} / \mathrm{min}$ using a C18 120 g column. Five fractions were then collected based on the solvent steps described above. During fractionation, a precipitate was formed in a tube of fraction F2, corresponding to compound 8 ( $2 \mathrm{mg}$ ). Fractions F1 (18.7 mg) and F2 (191 mg) retained biological activity and were subjected to further fractionation. Fraction F1 was purified by analytical HPLC (Luna PFP (2), mobile phase $\mathrm{H}_{2} \mathrm{O}+0.1 \% \mathrm{FA} / \mathrm{CH}_{3} \mathrm{OH}+0.1 \% \mathrm{FA}$, isocratic elution $95: 5$ over 35 minutes, flow rate $0.6 \mathrm{~mL} / \mathrm{min}$ ) to yield compound 18 (1.5 $\mathrm{mg}, \mathrm{RT}=8.2 \mathrm{~min})$ and $15(2.6 \mathrm{mg}, \mathrm{RT}=26.5 \mathrm{~min})$. Fraction $\mathrm{F} 2$ was purified by preparative HPLC (Luna PFP (2), mobile phase $\mathrm{H}_{2} \mathrm{O}+0.1 \% \mathrm{FA} / \mathrm{CH}_{3} \mathrm{CN}+0.1 \% \mathrm{FA}$, isocratic elution $88: 12$ over 30 minutes, flow rate $21 \mathrm{~mL} / \mathrm{min}$ ) to afford compound 6 (2.3 $\mathrm{mg}, \mathrm{RT}=14.8 \mathrm{~min}), 11(4.2 \mathrm{mg}, \mathrm{RT}=9.0 \mathrm{~min}$ ) and sub-fractions F2-4, F2-5, F2-6, F2-7, F2-8, F2-9, F2-11, and F2-13 that were subjected to further purification. Subfraction F2-4 (4.3 mg) was purified by analytical HPLC (Luna PFP (2), mobile phase $\mathrm{H}_{2} 0$ 
$+0.1 \% \mathrm{FA} / \mathrm{CH}_{3} \mathrm{OH}+0.1 \% \mathrm{FA}$, isocratic elution 85:15 over 40 minutes, flow rate 1 $\mathrm{mL} / \mathrm{min}$ ) to afford compounds 9 (0.4 $\mathrm{mg}, \mathrm{RT}=31.7 \mathrm{~min})$, and $\mathbf{1 0}(1.2 \mathrm{mg}, \mathrm{RT}=34.0$ min). Sub-fraction F2-5 (1.5 mg) was purified by analytical HPLC (Luna PFP (2), mobile phase $\mathrm{H}_{2} \mathrm{O}+0.1 \% \mathrm{FA} / \mathrm{CH}_{3} \mathrm{OH}+0.1 \% \mathrm{FA}$, isocratic elution 77:23 over 20 minutes, flow rate $1 \mathrm{~mL} / \mathrm{min}$ ) to afford compound $4(0.4 \mathrm{mg}$, RT = $17.8 \mathrm{~min})$. Sub-fraction F2-6 (10 mg) was purified by analytical HPLC (Luna PFP (2), mobile phase $\mathrm{H}_{2} 0+0.1 \%$ FA / $\mathrm{CH}_{3} \mathrm{OH}+0.1 \% \mathrm{FA}$, isocratic elution 80:20 over 30 minutes, flow rate $1 \mathrm{~mL} / \mathrm{min}$ ) to afford compounds 17 (1.5 mg, RT = $15.5 \mathrm{~min})$, and $\mathbf{5}(0.4 \mathrm{mg}, \mathrm{RT}=25.1 \mathrm{~min})$. Sub-fraction F2-7 (1.5 mg) was purified by analytical HPLC (Luna PFP (2), mobile phase $\mathrm{H}_{2} 0+0.1 \%$ FA / $\mathrm{CH}_{3} \mathrm{OH}+0.1 \% \mathrm{FA}$, isocratic elution $80: 20$ over 35 minutes, flow rate $1 \mathrm{~mL} / \mathrm{min}$ ) to yield compound 13 (0.2 mg, RT = $17.6 \mathrm{~min})$. Sub-fraction F2-8 (6 mg) was purified by analytical HPLC (Luna PFP (2), mobile phase $\mathrm{H}_{2} \mathrm{O}+0.1 \%$ FA $/ \mathrm{CH}_{3} \mathrm{OH}+0.1 \% \mathrm{FA}$, isocratic elution 80:20 over 25 minutes, flow rate $1 \mathrm{~mL} / \mathrm{min}$ ) to afford compounds 14 (2.1 mg, RT = $13.7 \mathrm{~min}), 7(1.3 \mathrm{mg}, \mathrm{RT}=17.0 \mathrm{~min})$, and $2(0.7 \mathrm{mg}, \mathrm{RT}=19.3 \mathrm{~min}) . \mathrm{Sub}-$ fraction F2-9 (3.1 mg) was purified by analytical HPLC (Luna PFP (2), mobile phase $\mathrm{H}_{2} 0$ $+0.1 \% \mathrm{FA} / \mathrm{CH}_{3} \mathrm{OH}+0.1 \% \mathrm{FA}$, isocratic elution 80:20 over 35 minutes, flow rate 1 $\mathrm{mL} / \mathrm{min}$ ) to yield compound 12 (1.4 mg, RT = $26.9 \mathrm{~min})$. Sub-fraction F2-11 (2.4 mg) was purified by analytical HPLC (Luna PFP (2), mobile phase $\mathrm{H}_{2} \mathrm{O}+0.1 \% \mathrm{FA} / \mathrm{CH}_{3} \mathrm{OH}+$ 0.1\% FA, isocratic elution 80:20 over 30 minutes, flow rate $1 \mathrm{~mL} / \mathrm{min}$ ) to afford compounds 3 (0.4 mg, RT = $21.7 \mathrm{~min})$, and 1 (0.5 mg, RT = $23.0 \mathrm{~min})$. Finally, subfraction F2-13 (4.9 mg) was purified by analytical HPLC (Luna PFP (2), mobile phase $\mathrm{H}_{2} \mathrm{O}+0.1 \% \mathrm{FA} / \mathrm{CH}_{3} \mathrm{OH}+0.1 \% \mathrm{FA}$, isocratic elution 60:40 over 12 minutes, flow rate 1 $\mathrm{mL} / \mathrm{min}$ ) to afford compound $16(0.7 \mathrm{mg}, \mathrm{RT}=8.0 \mathrm{~min})$.

All chemical descriptions of the isolated compounds (NMR, HREIMS) are available in the additional material section of this publication. 
Cell preparation method. The skin explant of a 53-year-old donor comes from abdominal surgery and is prepared (hypodermis eliminated) and provided by the BioEC Laboratory (Longjumeaux, France).

The explant (epidermis + dermis) is then cut into discs of about $1 \mathrm{~cm}$ in diameter. The discs are placed in a T75 culture flange, the dermis in contact with the plastic of the flange. After a few minutes of rest the discs adhere to the culture flange. Culture medium is added (10 mL of DMEM, 20\% FBS, 1\% antibiotic/antifungal medium) so that the skin discs are not completely covered.

The flask is then placed in the oven at $37^{\circ} \mathrm{C}, 5 \% \mathrm{CO} 2$, and the culture medium is changed every 3 days. About a week later, a heterogenous culture of fibroblasts and keratinocytes is observed in the mother box. When the cells have proliferated over the entire surface of the flask, the cells are detached with a trypsin solution and stored in liquid nitrogen. During the first culture starting again from the cryotubes, only the fibroblasts colonize the flask, in DMEM medium with 10\% FBS.

Before and during each test, cells are stained with trypan blue and counted using an automatic cell counter TC-20 (Bio-Rad, Marnes-la-Coquette, France). The cell viability of the counted sample is automatically analysed by the device according to the trypan blue exclusion principle. The percentage of viability of treated cells has always been above $95 \%$.

Biological activity - Immunofluorescence of CML. Dermal fibroblasts were plated at 5000 cells $/ \mathrm{cm}^{2}$ on glass coverslips set into a 24-wells-plate and cultured in DMEM supplemented with $10 \%$ FBS for 24 hours. On day 2, treatment with the molecules was done for 24 hours, at the concentration of $1 \mu \mathrm{g} / \mathrm{mL}$. On day 3, medium containing the 
treatment was removed, cells were washed with PBS, and fresh DMEM $+10 \%$ FBS medium was added in wells. On day 4, the fibroblasts were fixed with $2 \%$ paraformaldehyde solution for 12 minutes at room temperature, permeabilized with 0,2\% TritonX-100 solution for 10 minutes and finally blocked with $5 \%$ BSA, 0,2 \% Tween-20 solution for further 10 minutes. Cells were then incubated with the primary antibody anti-CML (mouse) at a concentration of $7 \mu \mathrm{g} / \mathrm{mL}$ at $4^{\circ} \mathrm{C}$ overnight, followed by incubation with Alexa-488 anti-mouse secondary antibody diluted at 1:200 for 2 hours at room temperature. After washing steps, coverslips were mounted onto microscope slides using a DAPI containing mounting medium and observed under a confocal photonic microscope (Spinning-Disk microscope, Roper/Nikon). Five images were recorded by coverslips (ten pictures per treatment condition). All pictures were taken with the same exposure time. Fluorescence quantification of images recorded was done using ImageJ software.

\section{UPLC-MS/MS analysis of SNB-CN13 extract}

Extract was diluted at $2 \mathrm{mg} / \mathrm{mL}$ in $\mathrm{MeOH}$. Metabolome profiling was conducted with a Thermo UHPLC-HRMS system. Analyses of extract (1.0 $\mu \mathrm{L}$ injected, $2 \mu$ g on column) was performed in electrospray positive ionisation mode in the 133.4-2000 Da range in centroid mode. The mass detector was an Orbitrap MS/MS FT Q-Exactive focus mass spectrometer. The analysis was conducted in FullMS data dependent MS $^{2}$ mode. In FullMS, resolution was set to 70,000 and AGC target was 3.106. In MS2, resolution was 17,500, AGC target $10^{5}$, isolation window $0.4 \mathrm{Da}$, normalized collision energy 30 , with 20 s dynamic exclusion. UHPLC column was a Phenomenex Luna Omega polar $\mathrm{C}_{18} 150 \times 2.1$ $\mathrm{mm}, 1.6 \mu \mathrm{m}$. The column temperature was set to $42{ }^{\circ} \mathrm{C}$, and the flow rate was 0.5 $\mathrm{mL} / \mathrm{min}$. The solvent system was a mixture of water $(\mathrm{A})$ with increasing proportions of 
acetonitrile (B), both solvents modified with $0.1 \%$ formic acid. The gradient was as follows: $2 \%$ B 3 min before injection, then from 1 min to 13 min, a linear increase of B up to $100 \%$ followed by $100 \%$ B for 5 min. The flow was discarded (not injected into the mass spectrometer) before injection and up to 1 min after injection.

\section{MZmine 2 Data preprocessing Parameters}

Raw files were directly processed using MZmine 2.32. The mass detection was realized keeping the noise at 20 . The chromatogram building was achieved using a minimum time span of $0.01 \mathrm{~min}$, minimum height of $1.0 \mathrm{E} 7$ and $\mathrm{m} / \mathrm{z}$ tolerance of 0.0015 or $5 \mathrm{ppm}$. The local minimum search deconvolution algorithm was used with the following settings: chromatographic threshold $=1 \%$, minimum retention time range $=0.05 \mathrm{~min}$, minimum relative height $=30 \%$, minimum absolute height $=5.0 \mathrm{E} 5$, minimum ratio of peak top/edge $=1$, and peak duration range $=0.01-5.0$ min. Chromatograms were deisotoped using the isotopic peaks grouper algorithm with an $m / z$ tolerance of 0.0015 or $5 \mathrm{ppm}$, and an RT tolerance of $0.1 \mathrm{~min}$. Peak alignment was performed using the RANSAC aligner method with the following parameters: $\mathrm{m} / \mathrm{z}$ tolerance $=0.0015$ or 5 ppm, absolute RT tolerance $=0.1 \mathrm{~min}$, absolute RT tolerance after correction $=0.5 \mathrm{~min}$, threshold value $=1$ ). The peak list was gap filled with the peak finder module (intensity tolerance at $50 \%, \mathrm{~m} / \mathrm{z}$ tolerance at 0.0015 or $5 \mathrm{ppm}$ and absolute RT tolerance of 0.1 $\min )$.

\section{Molecular Network analysis}

A molecular network was created using the online workflow at Global Natural Products Social Networking (GNPS) (http://gnps.ucsd.edu) (27). The data was filtered by removing all MS/MS peaks within +/- 17 Da of the precursor $m / z$. MS/MS spectra were 
window filtered by choosing only the top 6 peaks in the +/- 50 Da window throughout the spectrum. Precursor ion mass tolerance and fragment ion mass tolerance were set at 0.01 Da. Further, consensus spectra that contained less than 1 spectrum were discarded. A network was then created where edges were filtered to have a cosine score above 0.7 and more than 4 matched peaks. Further edges between two nodes were kept in the network if and only if each of the nodes appeared in each other's respective top 10 most similar nodes. The spectra in the network were then searched against GNPS' spectral libraries. The library spectra were filtered in the same manner as the input data. All matches kept between network spectra and library spectra were required to have a score above 0.7 and at least 4 matched peaks. Finally, molecular network was visualized using Cytoscape 3.4.0.

General procedure for the synthesis of symmetric 2,5-diketopiperazines. Thionyl chloride ( $\left.\mathrm{SOCl}_{2}, 1.67 \mathrm{~mL}, 22.9 \mathrm{mmol}\right)$ was added dropwise to a solution of amino acid (15.19 mmol) in methanol $(\mathrm{MeOH}, 25 \mathrm{~mL})$ at $0{ }^{\circ} \mathrm{C}$ under argon. The mixture was stirred for $19 \mathrm{~h}$ at room temperature. The solution was evaporated under reduced pressure. The residue was cooled at $0{ }^{\circ} \mathrm{C}$ and mixed with an aqueous solution of $\mathrm{K}_{2} \mathrm{CO}_{3}(50 \%, 2.5$ $\mathrm{mL}$ ) for 15 minutes. The solution was then extracted with tert-butyl methyl ether (TBME), and the organic phase was dried with $\mathrm{Na}_{2} \mathrm{SO}_{4}$ before being evaporated under reduced pressure. The oily residue was then heated for $17 \mathrm{~h}$ between 80 and $105^{\circ} \mathrm{C}$ depending on the amino acid used (Leu: $80{ }^{\circ} \mathrm{C}$; Met: $80{ }^{\circ} \mathrm{C}$; Pro: $\left.105^{\circ} \mathrm{C}\right)$. Then TBME $(2 \mathrm{x}$ $3 \mathrm{~mL}$ ) was added to the reaction mixture and the precipitate was collected by filtration after cooling to afford the corresponding symmetric 2,5-diketopiperazine. The NRM, HRMS and crystallographic descriptions of the synthetized molecules can be found in the supplementary material. 


\section{RESULTS AND DISCUSSION}

A preliminary examination of a bank of pure compounds and microbial extracts revealed that 2,5-diketopiperazines and an ethyl acetate extract of Sphingobacterium sp. SNBCN13 reduced the AGE content of dermal fibroblasts by 28 and $23 \%$, respectively (21). The working hypothesis of this work was that the activity of the Sphingobacterium sp. extract could be attributed to the presence of DKPs.

First, the SNB-CN13 extract was analyzed by LC-MS2. The collected data were used to build a molecular network to visualize the chemical diversity of the Sphingobacterium sp. extract (Fig. 1). Based on comparison with spectral databases and spectral similarities, we have identified two groups of related nodes containing DKPs in the network. By examining in detail the clustered $\mathrm{MS}^{2}$ spectra in these nodes, we have identified successive characteristic losses of $\mathrm{CO}(-27.9 \mathrm{Da}), \mathrm{NH}_{3}(-45.0 \mathrm{Da})$, and $\mathrm{CO}$ again $(-73.0 \mathrm{Da})$ from the parent ion, as well as characteristic fragment ions of amino acids residues formed after the cleavage of the amide bonds. A typical fragmentation scheme is provided in the supporting information (Scheme S1). Overall, this information confirmed the identification of the parent ions as pseudomolecular diketopiperazines ions (28). Overall, 26 presumed DKPs were found in the crude extract of Sphingobacterium sp. (Table S1). 


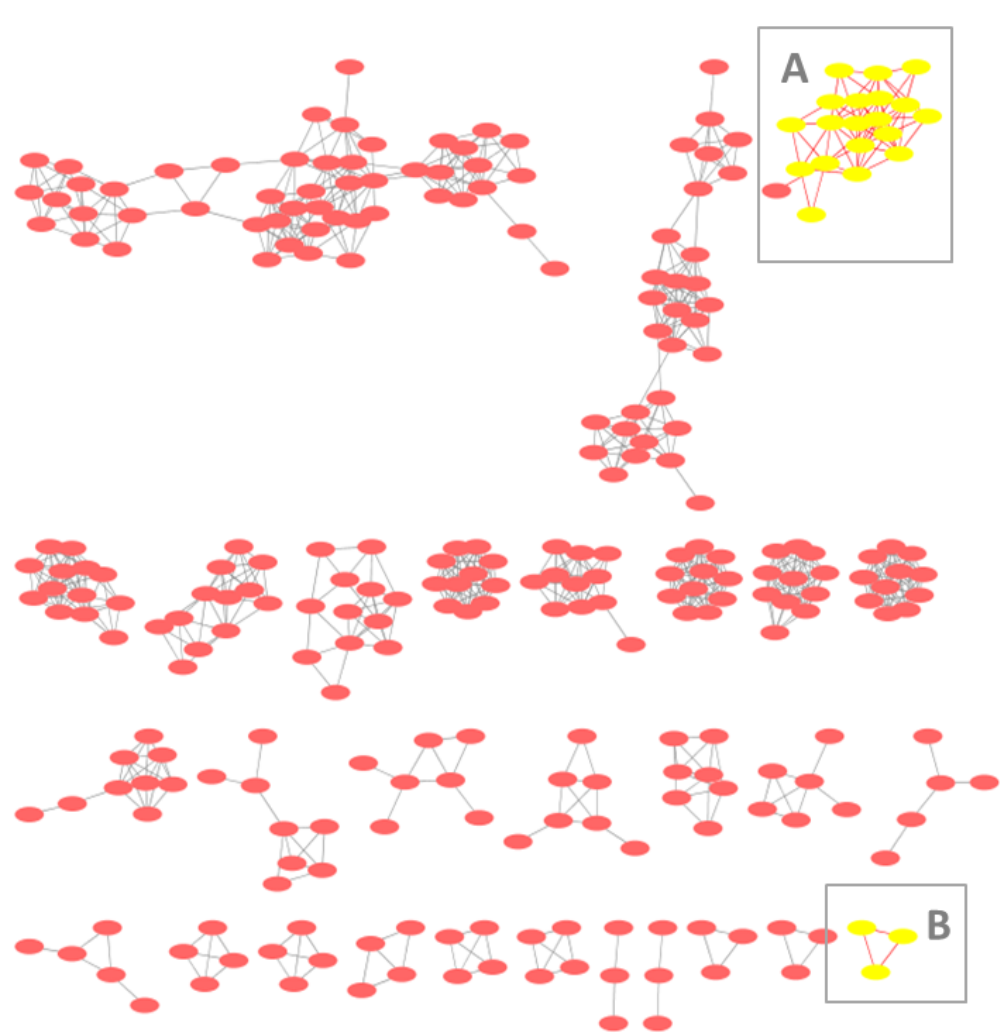

-

00000000000000000000
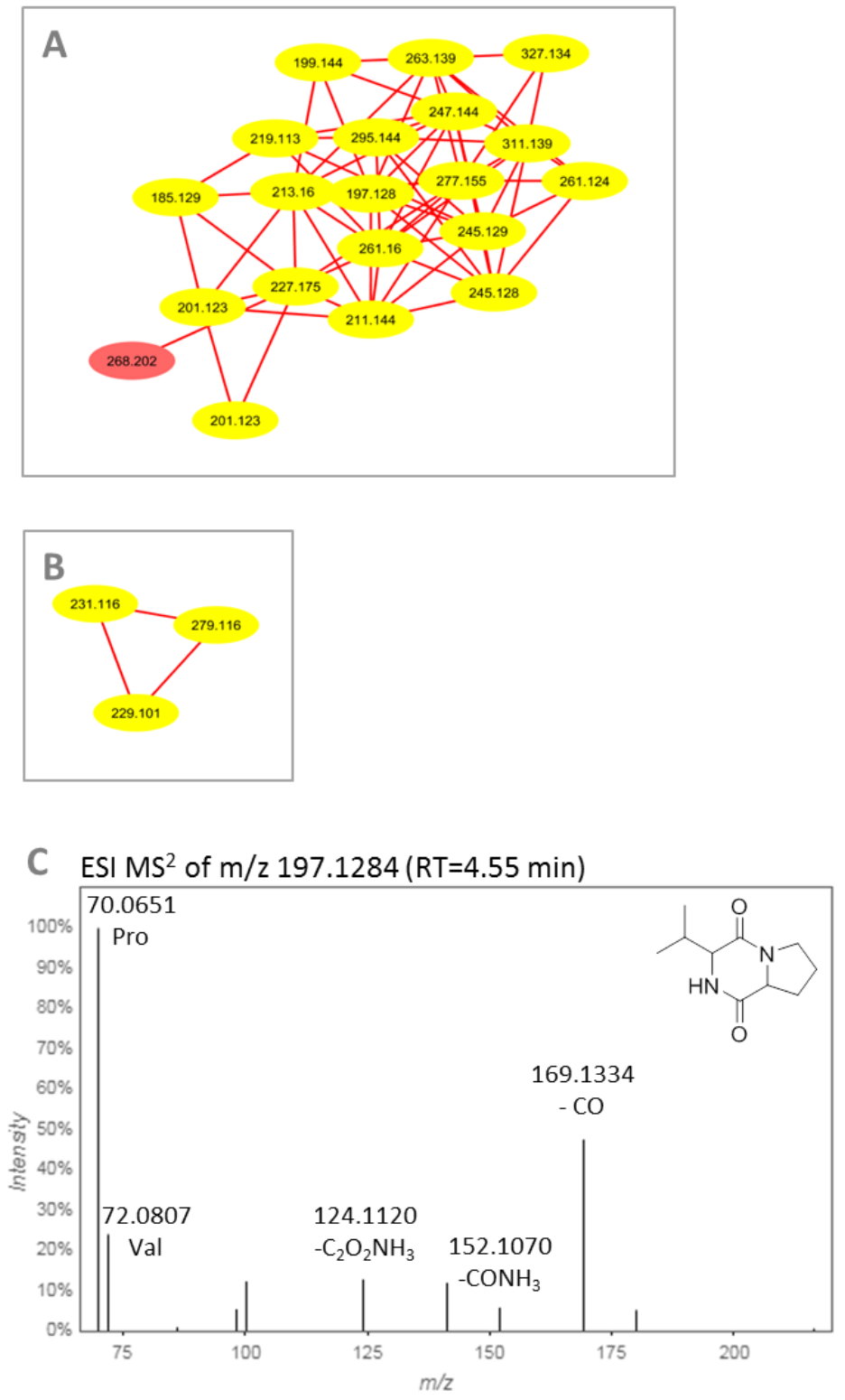

Figure 1. Molecular network of the crude extract of Sphingobacterium sp.. Clusters A and B contain DKP structures (yellow nodes). C. Example of MS $^{2}$ spectrum ( $/$ / $z$ 197.1284; RT $4.55 \mathrm{~min}$ ) showing ion fragments characteristic of amino acids and losses characteristic of the DKP skeleton. 
Bioguided fractionation of the crude extract was then carried out by flash chromatography and preparative HPLC, and twelve DKPs were isolated: cyclo(dehydoalanine-L-leucine) (1) (29), cyclo(dehydroalanine-L-isoleucine) (2) (29), cyclo(L-phenylalanine-L-alanine) (3) (30), cyclo(L-leucine-L-glutaric acid) (4) (31), cyclo(L-leucine-L-alanine) (5) (32), cyclo(L-tyrosine-L-valine) (6) (33), cyclo(Ltyrosine-L-tyrosine) (7) (34), cyclo(L-tyrosine-L-leucine) (8) (35), cyclo(L-proline-Lmethionine) (9) (36), cyclo(L-tyrosine-L-proline) (10) (36), cyclo(L-proline-L-valine) (11) (37), and cyclo(L-proline-L-isoleucine) (12) (38) (Fig. 2).<smiles>C=C1NC(=O)C(CC(C)C)NC1=O</smiles>

1<smiles>C=C1NC(=O)C([C@@H](C)CC)NC1=O</smiles>

2<smiles>C[C@H]1NC(=O)[C@H](Cc2ccccc2)NC1=O</smiles>

3<smiles>CC(C)C[C@@H]1NC(=O)C(CCC(=O)O)NC1=O</smiles>

4<smiles>CC(C)C[C@@H]1NC(=O)[C@H](C)NC1=O</smiles>

5<smiles>CC(C)[C@H]1NC(=O)[C@H](Cc2ccc(O)cc2)NC1=O</smiles>

6<smiles>O=C1N[C@H](Cc2ccc(O)cc2)C(=O)N[C@@H]1Cc1ccc(O)cc1</smiles>

7<smiles>CC(C)C[C@@H]1NC(=O)[C@H](Cc2ccc(O)cc2)NC1=O</smiles>

8<smiles>CC[C@H](C)[C@H]1NC(=O)[C@@H]2CCCN2C1=O</smiles>

12

Figure 2. 2,5-Diketopiperazines 1-12 isolated from the crude extract of SNB-CN13 by bioguided fractionation.

Six other molecules were also isolated during the fractionation: benzamide (13) (39), 2pyrrolecarboxylic acid (14) (40), glutaric acid (15) (41), 4-hydroxyphenylacetic acid (16) (42), 3-methylsulfanylpropionic acid (17) (43), and 3-methylsulfinylpropanoic acid (18) (43). 
All compounds were identified by comparison of their spectroscopic data and physicochemical properties with the reported in the literatures, and determined to be identical.

Following these results, the synthesis of diketopiperazines was studied. In order to develop a cosmetic ingredient for the organic market, the development strategy turned to a synthesis protocol based on the principles of green chemistry. In this process, amino acids were esterified with $\mathrm{MeOH} / \mathrm{HCl}$, and then condensed by heating after deprotonation of the amino group (Fig. 3) (44).

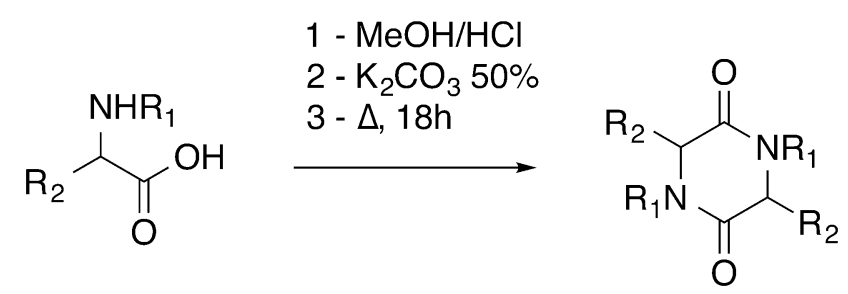

Figure 3. Synthesis process of symmetrical 2,5-DKP.

Using this protocol, the three symmetrical DKPs cyclo(L-leucine-L-leucine) (19), cyclo(L-methionine-L-methionine) (20), cyclo(L-proline-L-proline) (21) were obtained without epimerization (Fig. 4).<smiles>CC(C)C[C@@H]1NC(=O)[C@@H](CC(C)C)NC1=O</smiles>

19<smiles>CSCC[C@@H]1NC(=O)[C@@H](CCSC)NC1=O</smiles>

20<smiles>O=C1[C@@H]2CCCN2C(=O)[C@@H]2CCCN12</smiles>

21

Figure 4. Symmetrical 2,5-DKPs synthetized. 
The activity of the synthetic and isolated DKPs on the elimination of AGEs was then evaluated in human dermal fibroblasts. The in vitro test developed makes it possible to detect and quantify intracellular carboxymethyl lysine (CML) naturally formed and accumulated in human cells during aging, without using any glycation inducer. The decrease of the amount of CML in cells was evaluated by immunofluorescence. Compounds were tested at a concentration of $1 \mu \mathrm{g} / \mathrm{mL}$ for 24 hours.

The intracellular level of CML in untreated dermal fibroblasts from a 53-year-old donor was quite high, resulting in significant green fluorescence of the cells during photonic confocal microscopy observation (Fig. 5a - Fibroblasts treated with DMSO-control). Isolated (compounds 1-12) and synthesized (compounds 19-21) 2,5-diketopiperazines had a different impact on the green fluorescence of CML in fibroblasts. As shown in Fig. 5b, cyclo(L-Pro-L-Met) (9) have little or no effect on the intensity of green fluorescence of CML in treated fibroblasts. Fig. 5c (fibroblasts treated with cyclo(L-Leu-L-Leu) (19)), Fig. 5d (fibroblasts treated with cyclo(L-Met-L-Met) (20)) and Fig. 5e (fibroblasts treated with cyclo(L-Pro-L-Pro) (21)) show a reduction in green fluorescence of CML, indicating that these compounds have an effect on the elimination of CML accumulated with aging in dermal fibroblasts.

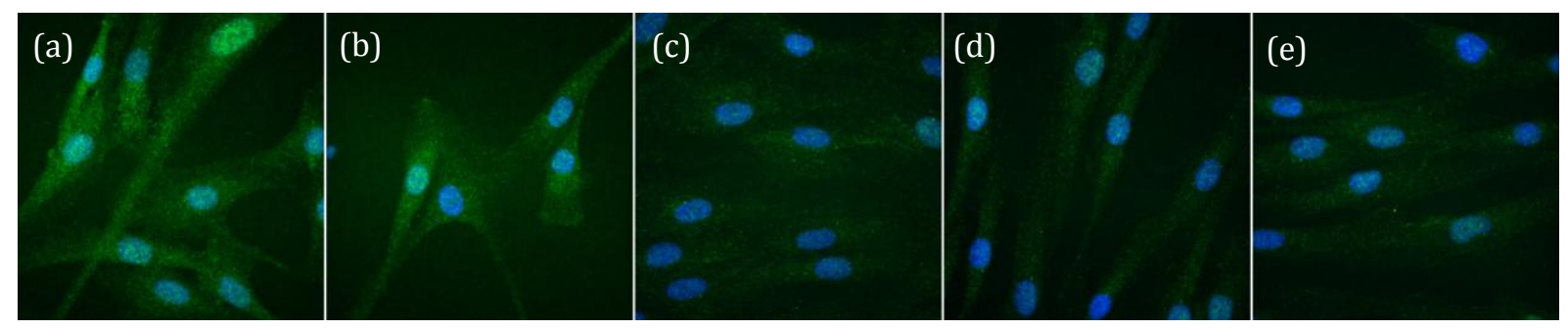

Figure 5. Confocal microscopy images (x 40) of human dermal fibroblasts treated for $24 \mathrm{~h}$ with (a) DMSO as control, (b) compound 9, (c) compound 19, (d) compound 20, and (e) compound 21 at $1 \mu \mathrm{g} / \mathrm{mL}$. The nucleus was labelled by DAPI (blue); The immunological labeling of CML was performed with Alexa 488 (green). 
The fluorescence of the images recorded under the confocal photonic microscope was quantified. The expression of CML in fibroblasts treated with molecules 1-12 and 19-21 was compared to the control. The results were expressed as a percentage of the decrease in CML compared to the control group for each treatment and are presented in Table I.

Table I. Percentage of decrease in CML in fibroblasts treated with molecules 1-21.

\begin{tabular}{|c|c|c|}
\hline Molecules & $\begin{array}{l}\text { Decrease of CML content } \\
\text { (\% compared to control) }\end{array}$ & $p$-value ${ }^{a}$ \\
\hline SNB-CN13 & $23.0 \pm 4.0$ & $* * *$ \\
\hline 1 cyclo(Dha-L-Leu) & $19.0 \pm 1.6$ & $* * *$ \\
\hline 2 cyclo(Dha-L-Ile) & $5.5 \pm 1.9$ & ns \\
\hline 3 cyclo(L-Phe-L-Ala) & $16.1 \pm 1.7$ & $* * *$ \\
\hline 4 cyclo(L-Leu-L-Glu) & $6.8 \pm 2.5$ & ns \\
\hline 5 cyclo(L-Leu-L-Ala) & $23.7 \pm 2.1$ & $* * *$ \\
\hline 6 cyclo(L-Tyr-L-Val) & $22.6 \pm 1.4$ & $* * *$ \\
\hline 7 cyclo(L-Tyr-L-Tyr) & $8.9 \pm 1.4$ & $*$ \\
\hline 8 cyclo(L-Tyr-L-Leu) & $23.4 \pm 1.1$ & $* * *$ \\
\hline 9 cyclo(L-Pro-L-Met) & $0.0 \pm 4.2$ & ns \\
\hline 10 cyclo(L-Tyr-L-Pro) & $17.0 \pm 1.5$ & $* * *$ \\
\hline 11 cyclo(L-Pro-L-Val) & $23.3 \pm 1.6$ & $* * *$ \\
\hline 12 cyclo(L-Pro-L-Ile) & $9.4 \pm 1.7$ & $*$ \\
\hline 19 cyclo(L-Leu-L-Leu) & $28.0 \pm 1.0$ & $* * *$ \\
\hline 20 cyclo(L-Met-L-Met) & $28.0 \pm 1.0$ & $* * *$ \\
\hline 21 cyclo(L-Pro-L-Pro) & $27.0 \pm 1.0$ & $* * *$ \\
\hline
\end{tabular}

aSignificance levels when compared to negative control were calculated by one-way Anova followed by Dunett's multiple comparison test. ${ }^{* * *} \mathrm{p}<0.001,{ }^{*} \mathrm{p}<0.05$, ns $=$ not significant

Among molecules 1-12 and 19-21, twelve of them significantly decreased the intracellular amount of CML in fibroblasts, with values ranging from $8.9 \%$ for cyclo(LTyr-L-Tyr) (7) to $28 \%$ for cyclo(L-Leu-L-Leu) (19). Cyclo(L-Met-L-Met) (20). Cyclo(Dha-L-Ile) (2), cyclo(L-Leu-L-Glu) (4) and cyclo(L-Pro-L-Met) (9) were inactive. It 
should also be noted that the symmetrical synthetic DKPs cyclo(L-Leu-L-Leu) (19), cyclo(L-Met-L-Met) (20) and cyclo(L-Pro-L-Pro) (21) showed the most important activity by significantly decreasing the intracellular amount of CML by 27.0-28.0\%.

Cell viability was assessed during cell counting using the trypan blue exclusion principle and revealed no decrease in fibroblast viability following treatment with diketopiperazines (viability $>95 \%$ ).

CML is a chemically very stable molecule. It is unlikely that the biological activity of DKP described in this paper results from a direct chemical action on CML. At the same time, it has been described that DKPs, due to their small steric size, are capable of binding to many cellular receptors (45). One of the hypotheses, which remains to be demonstrated, to explain the activity of diketopiperazines would be related to the AGER receptor. The AGER receptor has been described in many cells including fibroblasts (6). Its subunit 1 (AGER-1, OST 48), present on both the cell surface and the surface of the endoplasmic reticulum, specifically fixes terminal glycation products, without binding early glycation products such as Amadori products (46-48). The binding of intra- and extracellular AGEs to this receptor triggers their degradation, and has a protective effect against oxidative stress $(6,46)$. With age or in the case of diabetes, the level of AGEs in the body is high. In both cases, there is also a decrease in the expression of the AGER-1 receptor $(6,46)$.

This hypothesis that the activity of diketopiperazines on the elimination of AGEs in dermal fibroblasts is supported by an increase of a cellular detoxification process will have to be demonstrated in order to provide more details on the mechanism of action of diketopiperazines. 


\section{CONCLUSION}

In this article we describe for the first time that some molecules belonging to the 2,5diketopiperazine family act as detoxifying agents, capable of eliminating CML, a final AGE accumulated with age in dermal fibroblasts. 2,5-DKPs are natural cyclic dipeptides, produced by $90 \%$ of Gram-negative bacteria, but also by Gram-positive bacteria, fungi, plants and mammals. These molecules are also found in the human body (in the brain and human fluids) $(49,50)$, and in industrially processed food (beer, bread, meat, chocolate...) $(33,51)$.

We demonstrated that a de-replication strategy combining molecular network technique and MS2 data analysis was an effective tool to detect the presence of 26 potential DKPs in the crude extract of Sphingobacterium sp. SNB-CN13 and to predict their amino acid composition. The chemical study led to the isolation of 12 of the 26 diketopiperazines identified by the molecular network technique. Evaluation of the biological activity of the isolated DKPs showed that these molecules can remove advanced glycation end products present in the skin with age. It is interesting to note that symmetrical DKPs synthesized following the principles of green chemistry are also active on the same target.

Although the mode of action of the diketopiperazines remains to be confirmed, and given the elimination activity of advanced glycation end-products and the relative ease of synthesis of symmetrical compounds, diketopiperazines can be considered as compounds of interest for dermatological and cosmetic applications with an anti-ageing aim. 


\section{REFERENCES}

1. Maillard L. Action des acides aminés sur les sucres, formation des mélanoïdines par voie méthodique. Comptes rendus hebdomadaires des séances de l'Académie des Sciences. 1912;66- 8.

2. Vlassara H. Advanced Glycation in Health and Disease: Role of the Modern Environment. Ann N Y Acad Sci. 2005;1043(1):452- 60.

3. Kasper M, Funk RH. Age-related changes in cells and tissues due to advanced glycation end products (AGEs). Arch Gerontol Geriatr. juin 2001;32(3):233- 43.

4. Paul RG, Bailey AJ. The effect of advanced glycation end-product formation upon cell-matrix interactions. Int J Biochem Cell Biol. juin 1999;31(6):653- 60.

5. Valencia JV, Weldon SC, Quinn D, Kiers GH, DeGroot J, TeKoppele JM, et al. Advanced glycation end product ligands for the receptor for advanced glycation end products: biochemical characterization and formation kinetics. Anal Biochem. 1 janv 2004;324(1):68- 78 .

6. Ott C, Jacobs K, Haucke E, Navarrete Santos A, Grune T, Simm A. Role of advanced glycation end products in cellular signaling. Redox Biol. 2014;2:411- 29.

7. Liu Y, Liang C, Liu X, Liao B, Pan X, Ren Y, et al. AGEs increased migration and inflammatory responses of adventitial fibroblasts via RAGE, MAPK and NF-kappaB pathways. Atherosclerosis. janv 2010;208(1):34- 42.

8. Badenhorst D, Maseko M, Tsotetsi OJ, Naidoo A, Brooksbank R, Norton GR, et al. Cross-linking influences the impact of quantitative changes in myocardial collagen on cardiac stiffness and remodelling in hypertension in rats. Cardiovasc Res. mars 2003;57(3):632- 41.

9. Goldin A, Beckman JA, Schmidt AM, Creager MA. Advanced glycation end products: sparking the development of diabetic vascular injury. Circulation. 8 août 2006;114(6):597- 605.

10. Kume S, Takeya M, Mori T, Araki N, Suzuki H, Horiuchi S, et al. Immunohistochemical and ultrastructural detection of advanced glycation end products in atherosclerotic lesions of human aorta with a novel specific monoclonal antibody. Am J Pathol. sept 1995;147(3):654- 67.

11. Baynes JW. The role of AGEs in aging: causation or correlation. Exp Gerontol. sept 2001;36(9):1527- 37.

12. Gkogkolou P, Böhm M. Advanced glycation end products: Key players in skin aging? Dermatoendocrinol. 1 juill 2012;4(3):259- 70.

13. Kawabata K, Yoshikawa H, Saruwatari K, Akazawa Y, Inoue T, Kuze T, et al. The presence of $\mathrm{N}(\varepsilon)$-(Carboxymethyl) lysine in the human epidermis. Biochim Biophys Acta. oct 2011;1814(10):1246- 52. 
14. Lee EJ, Kim JY, Oh SH. Advanced glycation end products (AGEs) promote melanogenesis through receptor for AGEs. Sci Rep. 13 2016;6:27848.

15. Gkogkolou P, Böhm M. Advanced glycation end products: Key players in skin aging? Dermatoendocrinol. 1 juill 2012;4(3):259- 70.

16. Ogura Y, Kuwahara T, Akiyama M, Tajima S, Hattori K, Okamoto K, et al. Dermal carbonyl modification is related to the yellowish color change of photo-aged Japanese facial skin. J Dermatol Sci. 1 oct 2011;64(1):45- 52.

17. Reihsner R, Melling M, Pfeiler W, Menzel E-J. Alterations of biochemical and twodimensional biomechanical properties of human skin in diabetes mellitus as compared to effects of in vitro non-enzymatic glycation. Clin Biomech. 1 juin 2000;15(5):379- 86.

18. Crisan M, Taulescu M, Crisan D, Cosgarea R, Parvu A, Cãtoi C, et al. Expression of advanced glycation end-products on sun-exposed and non-exposed cutaneous sites during the ageing process in humans. PloS One. 2013;8(10):e75003.

19. Lee EJ, Kim JY, Oh SH. Advanced glycation end products (AGEs) promote melanogenesis through receptor for AGEs. Sci Rep. 13 2016;6:27848.

20. Dyer DG, Dunn JA, Thorpe SR, Bailie KE, Lyons TJ, McCance DR, et al. Accumulation of Maillard reaction products in skin collagen in diabetes and aging. J Clin Invest. juin 1993;91(6):2463- 9.

21. André A, Wdzieczak-Bakala J, Touré AK, Stien D, Eparvier V. A method to quantify intracellular glycation in dermal fibroblasts using liquid chromatography coupled to fluorescence detection - Application to the selection of deglycation compounds of dermatological interest. J Chromatogr B Analyt Technol Biomed Life Sci. 15 nov 2018;1100- 1101:100- 5 .

22. Otwinowski Z, Minor W. Processing of X-ray diffraction data collected in oscillation mode. Methods Enzymol. 1997;276:307- 26.

23. Sheldrick GM. SHELXT - integrated space-group and crystal-structure determination. Acta Crystallogr Sect Found Adv. janv 2015;71(Pt 1):3- 8.

24. Sheldrick GM. Crystal structure refinement with SHELXL. Acta Crystallogr Sect C Struct Chem. janv 2015;71(Pt 1):3- 8.

25. Farrugia LJ. WinGX and ORTEP for Windows: an update. J Appl Crystallogr. 2012;45(4):849- 54.

26. Nirma C, Eparvier V, Stien D. Antifungal agents from Pseudallescheria boydii SNBCN73 isolated from a Nasutitermes sp. termite. J Nat Prod. 24 mai 2013;76(5):988- 91.

27. Wang M, Carver JJ, Phelan VV, Sanchez LM, Garg N, Peng Y, et al. Sharing and community curation of mass spectrometry data with Global Natural Products Social Molecular Networking. Nat Biotechnol. 09 2016;34(8):828- 37. 
28. Xing J, Yang Z, Lv B, Xiang L. Rapid screening for cyclo-dopa and diketopiperazine alkaloids in crude extracts of Portulaca oleracea L. using liquid chromatography/tandem mass spectrometry. Rapid Commun Mass Spectrom RCM. mai 2008;22(9):1415- 22.

29. Kwon OS, Park SH, Yun BS, Pyun YR, Kim CJ. Cyclo(dehydroala-L-Leu), an alphaglucosidase inhibitor from Penicillium sp. F70614. J Antibiot (Tokyo). sept 2000;53(9):954- 8.

30. Sun X, Rai R, MacKerell AD, Faden AI, Xue F. Facile one-step synthesis of 2,5diketopiperazines. Tetrahedron Lett. 12 mars 2014;55(11):1905- 8.

31. Furukawa T, Akutagawa T, Funatani H, Uchida T, Hotta Y, Niwa M, et al. Cyclic dipeptides exhibit potency for scavenging radicals. Bioorg Med Chem. 15 mars 2012;20(6):2002- 9 .

32. Tian S, Yang Y, Liu K, Xiong Z, Xu L, Zhao L. Antimicrobial metabolites from a novel halophilic actinomycete Nocardiopsis terrae YIM 90022. Nat Prod Res. 2014;28(5):344- 6 .

33. Stark T, Hofmann T. Structures, sensory activity, and dose/response functions of 2,5-diketopiperazines in roasted cocoa nibs (Theobroma cacao). J Agric Food Chem. 7 sept 2005;53(18):7222- 31 .

34. Cochrane JR, White JM, Wille U, Hutton CA. Total synthesis of mycocyclosin. Org Lett. 4 mai 2012;14(9):2402- 5.

35. Scopel M, Abraham W-R, Henriques AT, Macedo AJ. Dipeptide cis-cyclo(LeucylTyrosyl) produced by sponge associated Penicillium sp. F37 inhibits biofilm formation of the pathogenic Staphylococcus epidermidis. Bioorg Med Chem Lett. 1 févr 2013;23(3):624- 6 .

36. Mehnaz S, Saleem RSZ, Yameen B, Pianet I, Schnakenburg G, Pietraszkiewicz H, et al. Lahorenoic acids A-C, ortho-dialkyl-substituted aromatic acids from the biocontrol strain Pseudomonas aurantiaca PB-St2. J Nat Prod. 22 févr 2013;76(2):135- 41.

37. Huang R, Yan T, Peng Y, Zhou X, Yang X, Liu Y. Diketopiperazines from the Marine Sponge Axinella sp. Chem Nat Compd. 1 mars 2014;50(1):191- 3.

38. Ren S, Ma W, Xu T, Lin X, Yin H, Yang B, et al. Two novel alkaloids from the South China Sea marine sponge Dysidea sp. J Antibiot (Tokyo). déc 2010;63(12):699- 701.

39. Bolyog-Nagy E, Udvardy A, Joó F, Kathó Á. Efficient and selective hydration of nitriles to amides in aqueous systems with $\mathrm{Ru}(\mathrm{II})$-phosphaurotropine catalysts. Tetrahedron Lett. 25 juin 2014;55(26):3615- 7.

40. Hübner H, Vierling W, Brandt W, Reiter M, Achenbach H. Minor constituents of Spigelia anthelmia and their cardiac activities. Phytochemistry. mai 2001;57(2):285- 96. 
41. Sirasani G, Tong L, Balskus EP. A biocompatible alkene hydrogenation merges organic synthesis with microbial metabolism. Angew Chem Int Ed Engl. 21 juill 2014;53(30):7785- 8.

42. Milne JE, Storz T, Colyer JT, Thiel OR, Dilmeghani Seran M, Larsen RD, et al. Iodidecatalyzed reductions: development of a synthesis of phenylacetic acids. J Org Chem. 18 nov 2011;76(22):9519- 24.

43. Crouch NP, Adlington RM, Baldwin JE, Lee M-Huee, MacKinnon CH. A mechanistic rationalisation for the substrate specificity of recombinant mammalian 4hydroxyphenylpyruvate dioxygenase (4-HPPD). Tetrahedron. 19 mai 1997;53(20):6993- 7010.

44. Zadel G, Breitmaier E. (5aS,10aS)-Octahydro-1H,5H-dipyrrolo[1,2-a:1',2Prime;d]pyrazin «DPP» als Hilfsreagenz bei der enantioselektiven 1,2-Addition von Grignard-Reagenzien an prochirale Carbonylverbindungen. Chem Ber. 1994;127(7):1323- 6.

45. Martins MB, Carvalho I. Diketopiperazines: biological activity and synthesis. Tetrahedron. 1 oct 2007;63(40):9923- 32.

46. Lu C, He JC, Cai W, Liu H, Zhu L, Vlassara H. Advanced glycation endproduct (AGE) receptor 1 is a negative regulator of the inflammatory response to AGE in mesangial cells. Proc Natl Acad Sci U S A. 10 août 2004;101(32):11767- 72.

47. Li YM, Mitsuhashi T, Wojciechowicz D, Shimizu N, Li J, Stitt A, et al. Molecular identity and cellular distribution of advanced glycation endproduct receptors: relationship of p60 to OST-48 and p90 to 80K-H membrane proteins. Proc Natl Acad Sci U S A. 1 oct 1996;93(20):11047- 52.

48. Cai W, He JC, Zhu L, Lu C, Vlassara H. Advanced glycation end product (AGE) receptor 1 suppresses cell oxidant stress and activation signaling via EGF receptor. Proc Natl Acad Sci. 12 sept 2006;103(37):13801- 6.

49. Prasad C. Food-Derived Neuroactive Cyclic Dipeptides. In: Nutrition, Brain and Behavior Series. CRC Publischers; p. 331- 40. (Nutritional Neuroscience; vol. 3).

50. Prasad C. Cyclo(His-Pro): its distribution, origin and function in the human. Neurosci Biobehav Rev. 1988;12(1):19- 22.

51. Gautschi M, Schmid JP, Peppard TL, Ryan TP, Tuorto RM, Yang X. Chemical Characterization of Diketopiperazines in Beer. J Agric Food Chem. 1 août 1997;45(8):3183- 9 . 